\title{
Effect of meteorological factors on the COVID-19 cases: a case study related to three major cities of the Kingdom of Saudi Arabia
}

\author{
Anam Iqbal ${ }^{1} \cdot{\text { Wajiha } \mathrm{Haq}^{2}}^{2} \cdot$ Tahir Mahmood $^{3,4} \cdot$ Syed Hassan Raza ${ }^{5}$
}

Received: 12 August 2021 / Accepted: 25 October 2021 / Published online: 12 November 2021

(c) The Author(s), under exclusive licence to Springer-Verlag GmbH Germany, part of Springer Nature 2021

\begin{abstract}
The COVID-19 pandemic affected the world through its ability to cause widespread infection. The Middle East including the Kingdom of Saudi Arabia (KSA) has also been hit by the COVID-19 pandemic like the rest of the world. This study aims to examine the relationships between meteorological factors and COVID-19 case counts in three cities of the KSA. The distribution of the COVID-19 case counts was observed for all three cities followed by cross-correlation analysis which was carried out to estimate the lag effects of meteorological factors on COVID-19 case counts. Moreover, the Poisson model and negative binomial (NB) model with their zero-inflated versions (i.e., ZIP and ZINB) were fitted to estimate city-specific impacts of weather variables on confirmed case counts, and the best model is evaluated by comparative analysis for each city. We found significant associations between meteorological factors and COVID-19 case counts in three cities of KSA. We also perceived that the ZINB model was the best fitted for COVID-19 case counts. In this case study, temperature, humidity, and wind speed were the factors that affected COVID-19 case counts. The results can be used to make policies to overcome this pandemic situation in the future such as deploying more resources through testing and tracking in such areas where we observe significantly higher wind speed or higher humidity. Moreover, the selected models can be used for predicting the probability of COVID-19 incidence across various regions.
\end{abstract}

Keywords COVID-19 · Cross-correlation analysis · Epidemiology · Middle East · Zero-inflated regression models · Temperature

\section{Introduction}

At the inception of COVID-19, health care providers in Wuhan, capital of Hubei, a province of China, reported

Responsible Editor: Lotfi Aleya

Wajiha Haq

dr.wajihahaq@s3h.nust.edu.pk

1 Department of Statistics, Government Graduate College for Women, Sargodha, Punjab, Pakistan

2 Department of Economics, School of Social Sciences and Humanities, National University of Sciences and Technology, Islamabad H-12, Pakistan

3 Industrial and Systems Engineering Department, King Fahd University of Petroleum and Minerals, Dhahran, Saudi Arabia

4 Interdisciplinary Research Centre for Smart Mobility \& Logistics, King Fahd University of Petroleum and Minerals, Dhahran, Saudi Arabia

5 School of Economics, Quaid-i-Azam University, Islamabad, Pakistan numerous cases of pneumonia by a known virus to the World Health Organization (WHO) on December 31, 2019. In January 2020, a novel virus was identified, and the samples were taken from cases (WHO 2020b). In February 2020, the WHO named it as coronavirus disease (COVID-19) (WHO 2020c) and referred to as acute respiratory syndrome coronavirus-2 (SARS-CoV-2) (Public Health England 2020). The World Health Organization (WHO) has officially announced the COVID-19 as a pandemic on March 11, 2020, due to the high contagiousness and widespread (WHO 2020d). The incubation period of the virus is argued to vary between 5 and 10 days (Chan et al. 2020; Guan et al. 2020). The initial manifestation may include cough, fever, sore throat, myalgia, anorexia, and breathing difficulties (Guan et al. 2020; Jiang et al. 2020). It is declared that the virus emanated in animals, and most of the cases came into view in the seafood market in Wuhan (HuangCL 2020; Rizwan et al. 2020; Haq et al. 2020). The genetics analysis and some clinical discoveries can be found in studies (Chan et al. 2020; Zhu et al. 2020) and references therein. It is not to deny that mRNA vaccine has been introduced in different parts of the world but yet 
the best knowledge about the behavior of the COVID-19 is to be investigated. Especially, it is yet to be known as our best knowledge that how meteorological factors can play an important role in the increase/decrease of infected cases.

Many studies on the COVID-19's influence have been concentrated on China (Gao et al. 2021; Lin et al. 2020), USA (Bashir et al. 2020; Sharma et al. 2021), and Europe (Menebo 2020; Yuan et al. 2021). There is a need to explore the virus's influence on the Middle East as well. This research focuses on the Kingdom of Saudi Arabia (KSA) that has been negatively affected. The Kingdom of Saudi Arabia (KSA) is the largest country in the Arabian Peninsula and thus had a higher risk in terms of infections and death from COVID-19 from the very beginning. After the identification of the first case on March 2, 2020, the number of cases increased rapidly, resulting in around 3,63,061 cases as of January 3, 2021. The Kingdom of Saudi Arabia (KSA) is located in the Middle East and has a 95\% desert area. It has a warm and dry climate with high temperatures during the day, unexpected drops in temperature at night, and very low annual rainfall in most of the country. The number of confirmed cases of COVID-19 started to rise quickly in the last week of March. The Saudi government took protective measures to minimize the destructive effects of COVID-19, such as suspension of Umrah, travel ban, closure of mosques for prayers, and curfew. On June 23, 2020, the Ministry of Hajj and Umrah declared that Hajj 2020 would be held with a restricted number of pilgrims. The Ministry of Health took serious measures during the Hajj 2020; pilgrims were required to quarantine themselves at hotel rooms for a week before arrival to perform Hajj, and they were asked to be carried on a safe social distance of $2 \mathrm{~m}$ and were split into groups of 20 individuals per group, who were followed by a guide throughout their whole Hajj performance (WHO 2020a). From March 2, 2020, to January 3, 2021, a total of around 3,63,061 COVID-19 cases have been reported in Saudi Arabia (Arab News 2020).

According to epidemiological studies, environmental circumstances may have influenced the spread of past outbreaks such as severe acute respiratory syndrome (SARS) and Middle East respiratory syndrome disease (MERS). The SARS epidemic was gradually faded with the warming weather coming and was basically ended in July 2003 (Cao et al. 2016; Tan et al. 2005; Wang et al. 2006). Some researchers suggested that climate change may have aided the emergence and spread of different viral diseases, including the SARS and MERS (Gale et al. 2010; Lofgren et al. 2007; Stott 2016). The previous studies presented that meteorological factors play an important role in the eruption of infectious diseases like influenza (Li 2011; Lowen et al. 2007; Shaman and Kohn 2009). Researchers in Korea discovered that low daily temperature and low/high relative humidity $(\mathrm{RH})$ greatly enhanced the risk of influenza, but that diurnal temperature range was positively connected with influenza incidence (DTR) (Park et al. 2020). As the coronavirus belongs to the same family of the influenza virus and has symptoms similar to colds, coughs, flu, and fever, it must be impacted by weather as well. Hence, it is essential to investigate the effects of many elements on COVID-19 instances, such as temperature, humidity, and wind speed. In this study, the authors aim to investigate the effect of weather-related variables on COVID-19 spread across the three most affected cities of KSA (i.e., Medina, Riyadh, and Jeddah). The relationships between meteorological factors and COVID-19 case counts in three cities of the KSA are not known to the best of our knowledge.

The rest of the article is organized as follows. In the next section, we provide literature review. The "Material and methods" section contains the study design, data collection methods, and analytical techniques used in this study. The "Results and discussion" section presents the results obtained using the analytical methods implemented for the data analysis and some discussion. Finally, we provide conclusions in the "Conclusion" section.

\section{Literature review}

COVID-19's most researched relationship is with meteorological conditions and air pollution, which influence coronavirus transmission and contribute to COVID-19's spread (Gao et al. 2021; Suhaimi et al. 2020). Some studies proposed that the COVID-19 epidemic might be affected by temperature and its alterations (Cao et al. 2016; Tan et al. 2005; Wang et al. 2006). Another research presents that the weather with low temperature, mild daytime temperature range, and low humidity favors the transmitting process of COVID-19 (Liu et al. 2020). The regional climatic condition might influence the COVID-19 outbreak (Mazhar Iqbal et al. 2020). It is suggested that weather is related to the spread of COVID-19, but the high temperature may not decrease the case counts without taking into account the execution of large-scale public health interventions (Luo et al. 2020). The literature (Luo et al. 2020; Wang et al. 2020) proposed that when examining a single-factor model in the higher temperature group, every $1{ }^{\circ} \mathrm{C}$ rise in minimum temperature is related to the decline of the cumulative number of COVID-19 by 0.86. In another study, it was noted that there was no association between COVID-19 outbreak and high temperature or ultraviolet (UV) radiation in Chinese cities (Yao et al. 2020). Oliveiros et al. (2020) reported that the temperature rise might not surely be related to the decline of COVID-19 case counts without taking into account containment measures.

Since the outbreak of COVID-19 in November 2019, several empirical studies have been conducted in China 
(Lin et al. 2020), the USA (Zangari et al. 2020), Brazil (Auler et al. 2020), and India (Jain and Sharma 2020). Menebo (2020) analyzed the correlation between the COVID-19 pandemic and components of weather in the capital city of Norway. Fu et al. (2021) studied the association of COVID-19 transmission with temperature, absolute humidity, and diurnal temperature range in the four European countries. Islam et al. (2021) found a substantial positive correlation between the minimum and mean temperature, wind speed, relative humidity, and absolute humidity, but contact transmission had no direct relationship with the number of COVID-19 confirmed cases in Bangladesh. Sarkodie and Owusu (2020) developed conceptual tools to compare confirmed cases, deaths, and recovery cases using dew/frost point, temperature, disaggregate temperature, wind speed, relative humidity, precipitation, and surface pressure. In literature, most of the studies were designed to highlight the COVID-19 impact on KSA public and health practitioners (see studies AlAhdal et al. 2012; Alsubaie et al. 2019; El-Masry et al. 2021; Nasar et al. 2020; Obied et al. 2020; Qadah 2020 and references therein).

To investigate the relationships between COVID-19 and meteorological conditions, several statistical and scientific methods are used. For instance, Khursheed et al. (2021) applied generalized additive model (GAM) and examined a non-linear relationship between meteorological factors and COVID-19 transmission with penalized spline methods. Yuan et al. (2021) studied the impact of meteorological variables on daily COVID-19 cases employing log-linear generalized additive model. Pani et al. (2020) investigated the connection between COVID19 and climatic indicators using Spearman and Kendall rank correlation tests. Zoran et al. (2020) conducted spatial analysis; quantile on quantile approach was used by Shahzad et al. (2020). Iqbal et al. (2020) used the wavelet approach to discover that temperature has no effect on COVID-19 instances. The M-SEIR model is used by Shi et al. (2020) to explain why there is no significant relationship between humidity and COVID-19.

In literature, most of the studies concluded that the countries that are now suffering the most from the COVID-19 epidemic are those that are located in colder climates. In regions with a warm, dry climate, there are few research exploring the relationship between meteorological parameters and COVID-19 cases. The current work hypothesizes a null relationship between the COVID-19 (confirmed cases) and meteorological parameters (temperature, humidity, and wind speed) in the three most infected cities of KSA using count modeling. The quest to find the factors affecting the disease will help manipulate the significant factors to control the disease.

\section{Material and methods}

This section introduces the study design, data collection methods, and the analytical approaches used to analyze the effect of meteorological factors on COVID-19 case counts.

\section{Study design and data collection}

A conspicuous increase in COVID-19 case counts was observed in Medina, Jeddah, and Riyadh, due to which we chose these cities to study the relationship between weather and case counts. Medina is the second holiest city for Muslims in the western region of Saudi Arabia. It has a desert climate with long and humid summers and short and windy winters. It is mostly clear all over the year with an average temperature of $81.4^{\circ} \mathrm{F}$. Riyadh is located on the eastern part of the Najd (central region) plateau with a hot desert climate with an average temperature of $77.7^{\circ} \mathrm{F}$ and low humidity throughout the year; its wettest month is April. Jeddah is situated in the western region of Saudi Arabia, the average high temperature is $84.2^{\circ} \mathrm{F}$, and November is its most wet month. The COVID-19 confirmed case counts in three cities were extracted from King Abdullah Petroleum Studies and Research Center (KAPSARC) Data Portal [https://datasource.kapsarc.org/] for the period of March 2 to July 15, 2020. The daily meteorological data containing average temperature, average relative humidity, and average wind speed (mph) were obtained from the website of weather underground [https:// www.wunderground.com/] from March 2 to July 15, 2020.

\section{Analytical technique}

A descriptive analysis was carried out to examine the characteristics of all variables in three cities, followed by a three-stage analysis. In the first stage, we fitted the Poisson, NB, ZIP, and ZINB distribution on the number of case counts for each city and estimated their parameters. Also, we performed diagnosis analysis based on the model selection criteria such as the Akaike information criterion (AIC) and Bayesian information criterion (BIC). In the second stage, cross-correlation analysis was conducted to identify the lag effects of meteorological factors that might be useful in predicting COVID-19 case counts. Then we adopted generalized linear models with Poisson and NB distribution. Moreover, we used zero-inflated versions of Poisson and NB models to estimate the city-specific case counts. The backward elimination method was applied to select the most significant meteorological factors in regression models. The structures of models used in this study are given below: 


\section{The Poisson model}

In count modeling, the most used technique is the Poisson regression model. It requires equidispersion that is the expected value of the response variable is equal to its variance. This technique is easy to use and permits zero counts and positive skewness (Cameron and Trivedi 2013). Let $\left(y_{i}, x_{i}\right)$ be an observation and $y_{i}$ given $x_{i}$ has Poisson distribution. Thus, the model can be formulated as:

$\ln \left(\mu_{i}\right)=X_{i}^{\prime} \beta ; \mu_{i}=e^{X_{i}^{\prime} \beta}$,

where $\mu_{i}$ is the mean vector, $X_{i}$ represents covariates, $X_{i}^{\prime}$ is the transpose of the vector $X_{i}$, and $\beta$ is the vector of unknown parameters. According to the equidispersion property, the conditional mean and variance of the Poisson regression model are $E\left(Y_{i} \mid X_{i}\right)=\operatorname{Var}\left(Y_{i} \mid X_{i}\right)=e^{X_{i}^{\prime} \beta}$. The estimation method for the Poisson regression model is maximum likelihood estimation (MLE). So the log-likelihood function for the response variable is defined as:

$\ln (l(Y, \beta))=\sum_{i=1}^{n}\left(y_{i}\left(\stackrel{\prime}{X}_{i} \beta\right)-\exp \left(X_{i \beta}-\ln y_{i} !\right)\right.$.

Furthermore, the parameter vector can be estimated iteratively using a Newton-Raphson and a Fisher scoring technique (Agresti 2003). The parameters are interpreted as: for one-unit change in an explanatory variable, the difference in the logs of the expected count is expected to change by the corresponding coefficient, given the other explanatory variables in the model are constant.

\section{The negative binomial (NB) model}

The Poisson model assumption (i.e., mean equals the variance) is often violated due to the heterogeneity in the data. Commonly, the NB regression model is used to model the overdispersed count data. It can be taken as the generalization of Poisson regression because it has the same mean structure as the Poisson regression and has an extra parameter to model the overdispersion. Let $\left(y_{i}, x_{i}\right)$ be an observation and $y_{i}$ given $x_{i}$ has NB distribution. Thus, the model can be formulated as:

$P\left(Y_{i}=y_{i} \mid X_{i}\right)=\frac{\Gamma\left(y_{i}+k\right)}{y_{i} ! \Gamma(k)}\left(\frac{\mu_{i}}{\mu_{i}+k}\right)^{y_{i}}\left(1+\frac{\mu_{i}}{k}\right)^{-k}, \mu_{i}>0, k>0$

The conditional mean and variance of the NB model are $E\left(Y_{i} \mid X_{i}\right)=\mu_{i}$ and $\operatorname{Var}\left(Y_{i} \mid X_{i}\right)=\mu_{i}+\mu_{i}^{2} / k$. The index $k$ represents the dispersion parameter. In NB regression model, the mean of the response variable is linked to a linear combination of explanatory variables by a log link function and given as:

$\ln \left(\mu_{i}\right)=X_{i}^{\prime} \beta ; \mu_{i}=e^{X_{i}^{\prime} \beta}$,

where $\mu_{i}$ is the mean vector, $X_{i}$ represents covariates, $X_{i}^{\prime}$ is the transpose of the vector $X_{i}$, and $\beta$ is the vector of unknown parameters. The parameters are estimated by the MLE method. So, the log-likelihood function for the response variable is given as:

$\ln (l(Y, k, \beta))=\sum_{i=1}^{n}\left\{y_{i} \ln \left(\frac{k e^{X_{i}^{\prime} \beta}}{1+k e^{X_{i}^{\prime} \beta}}\right)-k^{-1} \ln \left(1+k e^{X_{i}^{\prime} \beta}\right)+\ln \Gamma\left(y_{i}+k^{-1}\right)-\ln \Gamma\left(y_{i}+1\right)-\ln \Gamma\left(k^{-1}\right)\right\}$,

Similar to the Poisson model, in the NB model, the parameter vector can also be estimated by using the Newton-Raphson and a Fisher scoring method. To fit the NB model, package "MASS" (Venables et al. 2002) is used in R. Given that the other explanatory factors in the model are constant, a one-unit change in an explanatory variable is anticipated to affect the difference in the logs of the expected count by the corresponding coefficient.

\section{The zero-inflated Poisson (ZIP) model}

Sometimes, the cause of variation in the count data set might be an excess of zeros. In such a situation, the ordinary Poisson regression model is not suitable as it provides biased and inadequate estimates due to the violation of the equidispersion assumption. So, to get overcome the effect of excess zeros, an alternative to the ordinary Poisson regression model is proposed by Lambert (1992). In the proposed ZIP model, all zeros are grouped into two parts such as (i) first part models a proportion $(1-\psi) e^{-\mu_{i}}$ of zeros coming from Poisson distribution and zero inflation by incorporating zeros with a proportion $\psi$ and (ii) the second part models the non-zero counts that follow the Poisson distribution. Let the response variable be independent, and then the ZIP model is defined as:

$$
P\left(Y_{i}=y_{i} \mid X_{i}, Z_{i}\right)=\left\{\begin{array}{l}
\psi_{i}+\left(1-\psi_{i}\right) e^{-\mu_{i}} \text { if } y_{i}=0 \\
\left(1-\psi_{i}\right) \frac{e^{-\mu_{i}} \mu_{i}^{y_{i}}}{y_{i} !} \text { if } y_{i}>0
\end{array},\right.
$$

where $Z_{i}$ represents the vector of covariates describing the probability of excess zero $\psi_{i}$. The conditional mean and variance for the ZIP regression model are $E\left(Y_{i} \mid X_{i}, Z_{i}\right)=\left(1-\psi_{i}\right) \mu_{i}$ and $\operatorname{Var}\left(Y_{i} \mid X_{i}, Z_{i}\right)=\left(1-\psi_{i}\right)\left(\mu_{i}+\psi_{i} \mu_{i}^{2}\right)$. The ZIP model is formulated by adding the following two link functions: 
$\ln \left(\mu_{i}\right)=e^{X_{i}^{\prime} \beta} ; \operatorname{logit}\left(\psi_{i}\right)=\ln \frac{\psi_{i}}{1-\psi_{i}}=e^{Z_{i}^{\prime} \gamma}$.

In the ZIP model, $\psi_{i}$ is modeled as:

$\psi_{i}=\frac{e^{Z_{i}^{\prime} \gamma}}{1+e^{Z_{i}^{\prime} \gamma}}$,

where $X_{i}^{\prime}$ is the vector of covariates, $Z_{i}^{\prime}$ is the vector of covariates for defining the probability of excess zero $\psi_{i}$, and $\beta$ and $\gamma$ are the vectors of unknown parameters. For estimation of parameters, the log-likelihood function for the response variable is defined as:

$\ln (l(Y, \beta, \gamma))=\sum_{y_{i}=0} \ln \left[\exp \left(Z_{i}^{\prime} \gamma\right)+\exp \left(-\exp \left(X_{i}^{\prime} \beta\right)\right)\right]$

$+\sum_{y_{i}>0}\left[Y_{i} \exp \left(X_{i}^{\prime} \beta\right)-\exp \left(X_{i}^{\prime} \beta\right) \ln \left(y_{i} !\right)\right]-\sum_{i=1}^{n} \ln \left[1+\exp \left(Z_{i}^{\prime} \gamma\right)\right]$.

Let $I_{i}$ be an indicator variable which is defined as follows:

$I_{i}=\left\{\begin{array}{l}1, \text { if } y_{i}=0 \\ 0, \text { if } y_{i}>0\end{array}\right.$

Then the log-likelihood function takes the form:

$$
\begin{aligned}
& \ln (l(Y, \beta, \gamma))=\sum_{y_{i}=0} I_{i} \ln \left[\exp \left(Z_{i}^{\prime} \gamma\right)+\exp \left(-\exp \left(X_{i}^{\prime} \beta\right)\right)\right] \\
& +\sum_{y_{i}>0}\left(1-I_{i}\right)\left[Y_{i} \exp \left(X_{i}^{\prime} \beta\right)-\exp \left(X_{i}^{\prime} \beta\right)-\ln \left(y_{i} !\right)\right]-\sum_{i=1}^{n} \ln \left[1+\exp \left(Z_{i}^{\prime} \gamma\right)\right] .
\end{aligned}
$$

Furthermore, the expectation-maximization (EM) algorithm can be used to maximize the log-likelihood function iteratively (Lambert 1992). To fit the ZIP model, package "pscl" (Jackman 2010) is employed in R. The interpretation of the parameter $\beta$ is same as in Poisson regression, but the parameter $\gamma$ can be interpreted by the odds ratio (Lambert 1992

\section{The zero-inflated negative binomial model}

The data is mostly overdispersed due to heterogeneity in the data, and the ZINB distribution is used to model such data (Haq et al. 2020). The ZINB distribution is a continuous mixture of Poisson distribution, and it allows the Poisson mean to be gamma distributed to model the overdispersion. Similar to the ZIP model, in ZINB, all zeros are grouped into two parts such as (i) first part model a proportion $(1-\psi)\left(1+\frac{\mu_{i}}{\tau}\right)^{-\tau}$ of zeros coming from NB distribution and zero inflation by incorporating zeros with a proportion $\psi$ and (ii) the second part models the non-zero counts that follow ordinary NB distribution. The ZINB regression model is defined as follows:

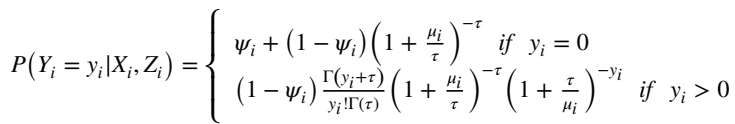

where $Z_{i}$ is the vector of covariates describing the probability of excess zero $\psi_{i}$. The conditional mean and variance of $\mathrm{t} \mathrm{h} \mathrm{e} \quad \mathrm{Z} \mathrm{I} \mathrm{N} \mathrm{B} \quad \mathrm{mod} \mathrm{e} \quad$ a r e $E\left(Y_{i} \mid X_{i}, Z_{i}\right)=\left(1-\psi_{i}\right) \mu_{i}$ Italic and $\operatorname{Var}\left(Y_{i} \mid X_{i}, Z_{i}\right)=\mu_{i}\left(1-\psi_{i}\right)\left(1+\psi_{i} \mu_{i}+\mu_{i} / \tau\right)$, where $\tau$ is the dispersion parameter. The ZINB model is formulated by adding the following two link functions:

$\ln \left(\mu_{i}\right)=e^{X_{i}^{\prime} \beta} ; \operatorname{logit}\left(\psi_{i}\right)=\ln \frac{\psi_{i}}{1-\psi_{i}}=e^{Z_{i}^{\prime} \gamma}$.

In the ZINB model, $\psi_{i}$ is modeled as:

$\psi_{i}=\frac{e^{Z_{i}^{\prime} \gamma}}{1+e^{Z_{i}^{\prime} \gamma}}$.

where ${ }^{\prime}{ }_{i}$ is the vector of covariates, ${ }^{\prime}{ }_{i}$ is the vector of covariates for defining the probability of excess zero $\psi_{i}$, and $\beta$ and $\gamma$ are the vectors of unknown parameters. The ZINB loglikelihood function is defined as:

$\ln (l(Y, \beta, \gamma, \tau))=\sum_{i=1}^{n} \ln \left(1+e^{Z_{i}^{\prime} \gamma}\right)-\sum_{i: y_{i}=0} \ln \left(e^{z_{i}^{\prime} \gamma}+\left(\frac{e^{X_{i}^{\prime} \beta}+\tau}{\tau}\right)^{-\tau}\right)$

$+\sum_{i: y_{i}>0} \ln \left(\tau\left(\frac{e^{X_{i}^{\prime} \beta}+\tau}{\tau}\right)+y_{i} \ln \left(1+e^{x_{i}^{\prime} \beta^{\prime}} \tau\right)\right)$

$+\sum_{i: y_{i}>0} \ln (\Gamma(\tau))+\ln \left(\Gamma\left(1+y_{i}\right)\right)-\ln \left(\Gamma\left(\tau+y_{i}\right)\right)$

The Broyden-Fletcher-Goldfarb-Shanno (BFGS) algorithm is used to estimate the parameters of the ZINB model (Mahmood 2020). To fit the ZINB model, package "pscl" (Jackman 2010) is employed in R. The interpretation of the parameter $\beta$ is the same as in Poisson regression, but the parameter $\gamma$ can be interpreted by the odds ratio.

The autocorrelation is usually more robust in residuals from time series regression of infectious diseases (Cameron and Trivedi 2013); for that reason, in these models, the response variable (daily COVID-19 case counts) was introduced as an explanatory variable at 1-day lag. No obvious seasonal variation and long-term trend of case counts in three cities were perceived during this period (see Fig. 1).

\section{Model selection}

The selection of a suitable model is an essential step for data modeling. The choice of a wrong model may lead to estimation errors and false conclusions. Therefore, in the 
(a)

(b)
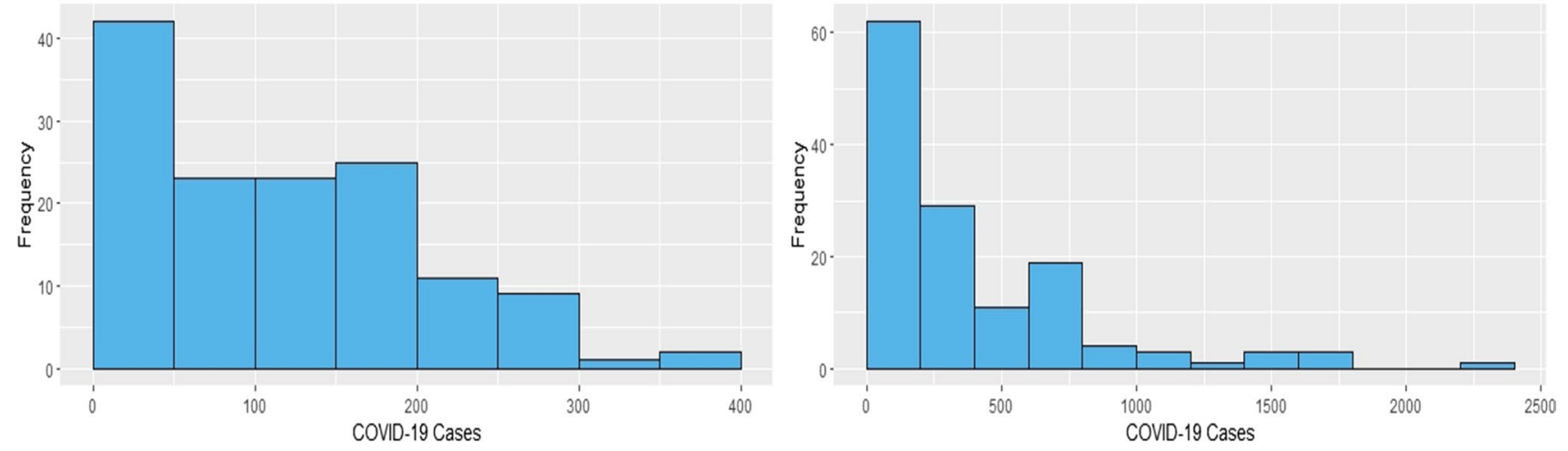

(c)

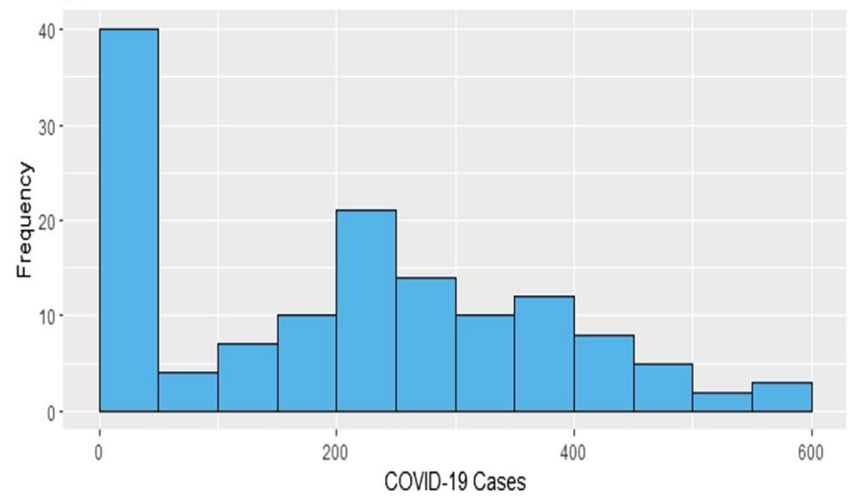

Fig. 1 Daily COVID-19 case counts in three cities of KSA (i.e., a about Medina, b about Riyadh, and $\mathbf{c}$ about Jeddah) during the period of March 2 to July 15, 2020

third stage of analysis, we have used a two-step procedure known as the LRT-Vuong method; the procedure is given in Mahmood (2020) and references therein. The likelihood ratio test (LRT) is used to test overdispersion in the data, and for testing zero inflation in the data, the Vuong test is used. The Poisson model is a special case of the NB model; therefore, the former is considered an alternative model. Under LRT, the hypothesis is $H_{0}: \tau=0$, versus $H_{1}: \tau>0$. So, for the general NB regression model, the LRT for $\tau$ is defined as:

$L R T_{\tau}=-2(l(Y, \hat{\beta})-l(Y, \hat{\beta}, \hat{\tau}))$,

where $l(Y, \hat{\beta})$ is the maximized log-likelihood under the Poisson model and $l(Y, \widehat{\beta}, \hat{\tau})$ is the maximized log-likelihood under the NB model. It is assumed that, under the null hypothesis, the LRT statistic follows a chi-square distribution with one degree of freedom, and the test provides evidence of overdispersion in case of significant results.
The Vuong (Vuong 1989) test is used to choose between the Poisson model and the ZIP model or NB model and ZINB model. Let $P\left(Y_{i}=y_{i} \mid X_{i}\right)$ be the predicted probability of response variable from the standard model and $P\left(Y_{i}=y_{i} \mid X_{i}, Z_{i}\right)$ be the predicted probability of response variable from the zero inflation model, and then the statistic $m_{i}$ be defined as:

$m_{i}=\log \left(\log \frac{P\left(Y_{i}=y_{i} \mid X_{i}\right)}{P\left(Y_{i}=y_{i} \mid X_{i}, Z_{i}\right)}\right)$.

Thus, Vuong's statistic for testing the nested hypothesis of standard model versus inflation model, i.e., $H_{0}: E\left(m_{i}\right)=0$ versus $H_{1}: E\left(m_{i}\right) \neq 0$, is defined as:

$V=\frac{\sqrt{n}\left(\frac{1}{n} \sum_{i=1}^{n} m_{i}\right)}{\sqrt{\frac{1}{n}} \sum_{i=1}^{n}\left(m_{i}-\frac{1}{n} \sum_{i=1}^{n} m_{i}\right)^{2}}$. 
Under the null hypothesis, Vuong's statistic follows normal distribution. At 5\% level of significance, when $V>1.96$, the standard model is chosen, when $V<-1.96$, the zeroinflated model is chosen, and $|V|<1.96$, then both models are assumed equivalent.

For the assessment of overdispersion, we first applied both Poisson and NB models to the data of each city. Furthermore, the LRT test was utilized to examine whether the NB model gives the best fits or the Poisson model. The significant findings of the NB model give evidence of overdispersion in the data set. In the second step, we had used the Vuong test. In the case of overdispersion, the NB model was compared with the ZINB model; otherwise, the Poisson model was compared with the ZIP model. If the zero-inflated model yields a better fit as compared to the ordinary model, then it reveals zero inflation in the data. Hence, in the case of zero inflation, the zero-inflated model is effective for estimation and drawing conclusions. It is also to be noted that all analyses were conducted using $\mathrm{R}$ software with version 3.6.2.

\section{Results and discussion}

The descriptive results for all variables are presented in Table 1. A total of 95,115 cases were officially reported in three cities of KSA from March 2 to July 15, 2020. Among the three cities, the average daily case counts were high in Riyadh with a large variance. During our study period, the daily average temperatures for Medina, Riyadh, and Jeddah

Table 1 Descriptive statistics for meteorological factors and COVID19 case counts in three cities from January 2 to July 15,2020

\begin{tabular}{|c|c|c|c|c|c|}
\hline City & Variables & Mean & Variance & Maximum & Minimum \\
\hline \multirow[t]{4}{*}{ Medina } & Cases & 114.6 & 8861.7 & 396 & 0 \\
\hline & $\begin{array}{l}\text { Temperature } \\
\left({ }^{\circ} \mathrm{F}\right)\end{array}$ & 88.92 & 90.90 & 104.4 & 66.4 \\
\hline & Humidity (\%) & 14.19 & 42.44 & 37.8 & 5.4 \\
\hline & $\begin{array}{l}\text { Wind speed } \\
(\mathrm{mph})\end{array}$ & 7.17 & 4.17 & 14.1 & 3.6 \\
\hline \multirow[t]{4}{*}{ Riyadh } & Cases & 376.07 & $184,084.31$ & 2371 & 0 \\
\hline & $\begin{array}{l}\text { Temperature } \\
\left({ }^{\circ} \mathrm{F}\right)\end{array}$ & 86.98 & 115.96 & 102.5 & 62.9 \\
\hline & Humidity (\%) & 22.85 & 95.03 & 68.5 & 10.9 \\
\hline & $\begin{array}{l}\text { Wind speed } \\
(\mathrm{mph})\end{array}$ & 7.01 & 6.35 & 13.8 & 2.1 \\
\hline \multirow[t]{4}{*}{ Jeddah } & Cases & 208.70 & $26,447.13$ & 586 & 0 \\
\hline & $\begin{array}{l}\text { Temperature } \\
\left({ }^{\circ} \mathrm{F}\right)\end{array}$ & 85.44 & 38.79 & 97.2 & 73.2 \\
\hline & Humidity (\%) & 50.56 & 92.78 & 71.7 & 26.5 \\
\hline & $\begin{array}{l}\text { Wind speed } \\
(\mathrm{mph})\end{array}$ & 9.36 & 7.19 & 17.4 & 3.1 \\
\hline
\end{tabular}

were $88.92^{\circ} \mathrm{F}, 86.98^{\circ} \mathrm{F}$, and $85.44^{\circ} \mathrm{F}$, respectively. Medina city had a smaller number of cases with the highest average temperature, and Jeddah city had the lowest average temperature but with large case counts as compared to Medina. The humidity and wind speed were relatively higher in Jeddah than in the other two cities.

The distribution of COVID-19 case counts in three cities can be seen in Fig. 2. The distribution results for COVID-19 case counts in three cities are given in Table 2. We found that AIC and BIC were smaller for ZIP as compared to Poisson distribution and smaller for ZINB as compared to NB distribution. Overall, ZINB distribution fitted better the case counts in all three cities.

In cross-correlation analysis (cf. Table 3), we found a significant positive association between daily cases and temperature on the same day and at 1- to 3-day lag for Medina. In Riyadh, daily cases were significantly and positively associated with the temperature on the same day and at 1- to 3-day lag. A significant negative association was noticed between daily case counts and humidity on the same day and at 1- to 3-day lag. Similarly, a significant negative association was also found between daily cases and wind speed on the same day and at 1- to 3-day lag, which is in consensus with the previous study by Rendana (2020). We observed that, in Jeddah, there was a significant positive relationship between daily cases and temperature on the same day and at 1- to 3-day lag. So, our results confirmed that weather conditions influence COVID-19 case counts, and this finding is in line with previous studies on infectious diseases (Cao et al. 2016; Li 2011; Lowen et al. 2007; Tan et al. 2005). All significant lagged variables were included in city-specific regression models.

The Poisson regression analysis results for Medina (cf. Table 4) revealed that the daily cases at 1-day lag had a significant positive impact on COVID-19 daily case counts. A $1{ }^{\circ} \mathrm{F}$ increase in temperature at 2-day lag was associated with an increase in daily COVID-19 case counts. However, each $1^{\circ} \mathrm{F}$ increase in temperature at 3-day lag was related to the decline in the number of daily cases. From ZIP regression analysis, we found that daily cases at 1-day lag had a significant positive effect on daily case counts. Each $1^{\circ} \mathrm{F}$ increase in temperature at 2-day lag led to a rise in the number of cases. At the same time, each $1^{\circ} \mathrm{F}$ increase in temperature on the same day and at 3-day lag was related to declining in case counts. We also found that the probability of COVID19 occurrence was negatively related to the temperature on the same day. From NB and ZINB regression analysis results (cf. Table 4), it was observed that one unit increase in daily cases at 1-day lag and $1^{\circ} \mathrm{F}$ increase in temperature at 1 - and 2-day lag were likely to increase daily case counts. Also, the probability of COVID-19 occurrence was negatively related to the temperature on the same day. The studies (Liu et al. 
(a)

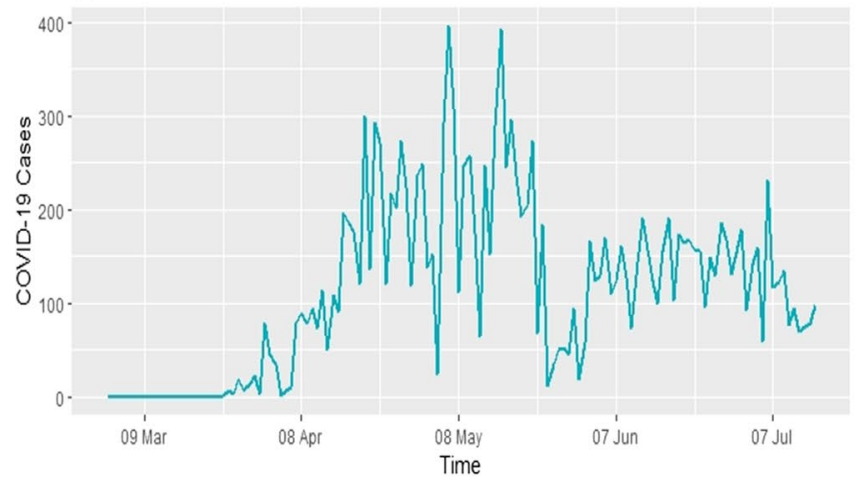

(c)

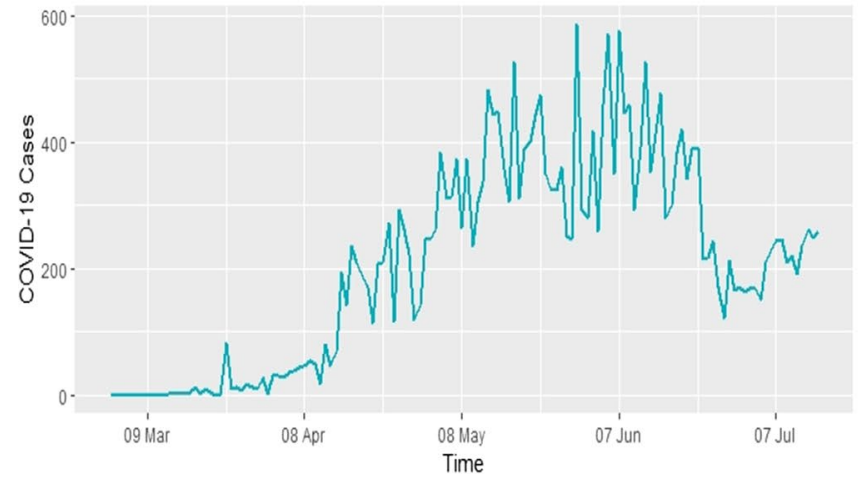

(b)

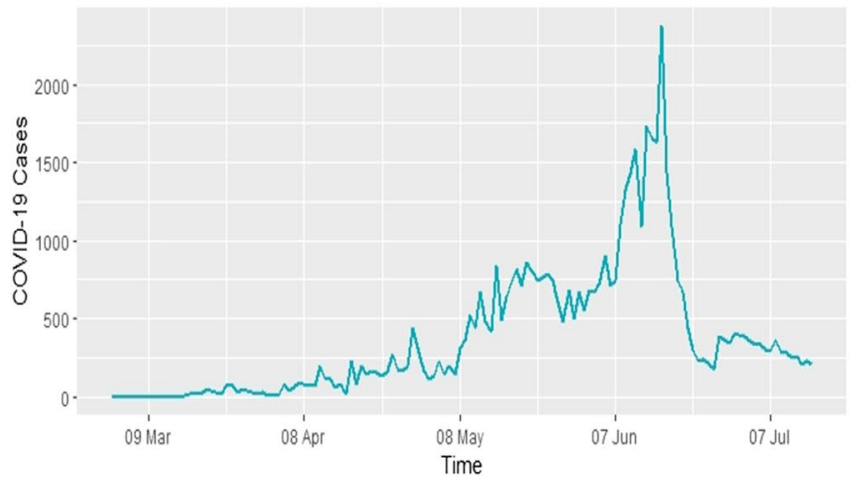

Fig. 2 Distribution of COVID-19 case counts in three cities of KSA such as a about Medina, b about Riyadh, and $\mathbf{c}$ about Jeddah

Table 2 Output of best-fitted distribution for COVID-19 case counts in three cities

\begin{tabular}{|c|c|c|c|c|}
\hline & Poisson & NB & ZIP & ZINB \\
\hline \multicolumn{5}{|l|}{ Medina } \\
\hline Parameters & $114.60(0.92)$ & $\begin{array}{l}0.52(0.06) \\
114.59(13.69)\end{array}$ & $\begin{array}{l}4.92(0.01) \\
1.70(0.24)\end{array}$ & $\begin{array}{l}4.91(0.08) \\
0.38(0.13) \\
-1.7(0.24)\end{array}$ \\
\hline Log-likelihood & -6527.21 & -763.43 & -3971.60 & -733.87 \\
\hline AIC & $13,056.42$ & 1530.85 & 7947.11 & 1473.75 \\
\hline $\mathrm{BIC}$ & $13,059.33$ & 1536.68 & 7953.02 & 1482.48 \\
\hline \multicolumn{5}{|l|}{ Riyadh } \\
\hline Parameters & 376.07 (1.67) & $\begin{array}{l}0.53(0.06) \\
376.01(44.17)\end{array}$ & $\begin{array}{l}6.01(0.004) \\
-2.53(0.33)\end{array}$ & $\begin{array}{l}5.91(0.10) \\
-0.26(0.12) \\
-2.65(0.37)\end{array}$ \\
\hline Log-likelihood & $-29,121.11$ & -922.96 & $-25,250.67$ & -915.94 \\
\hline AIC & $58,244.23$ & 1849.92 & $50,505.33$ & 1837.87 \\
\hline BIC & $58,247.14$ & 1855.75 & $50,511.16$ & 1846.61 \\
\hline \multicolumn{5}{|l|}{ Jeddah } \\
\hline Parameters & $188.82(1.18)$ & $\begin{array}{l}0.57(0.06) \\
188.86(21.49)\end{array}$ & $\begin{array}{l}5.33(0.01) \\
-2.35(0.30)\end{array}$ & $\begin{array}{l}5.33(0.09) \\
-0.09(0.13) \\
-2.42(0.33)\end{array}$ \\
\hline Log-likelihood & $-11,171.04$ & -834.71 & -8839.57 & -825.34 \\
\hline AIC & $22,344.08$ & 1673.42 & $17,683.15$ & 1656.68 \\
\hline $\mathrm{BIC}$ & $22,346.99$ & 1679.24 & $17,688.97$ & 1665.42 \\
\hline
\end{tabular}


Table 3 Cross-correlation coefficients between daily COVID-19 case counts and meteorological factors in three cities

\begin{tabular}{lllll}
\hline City & Lag (days) & Temperature & & \\
Medina & 0 & 0.415 & & \\
& 1 & 0.418 & & \\
& 2 & 0.422 & & \\
& 3 & 0.399 & & \\
City & Lag (days) & Temperature & Humidity & Wind speed \\
Riyadh & 0 & 0.601 & -0.435 & -0.301 \\
& 1 & 0.591 & -0.422 & -0.334 \\
& 2 & 0.579 & -0.420 & -0.310 \\
& 3 & 0.574 & -0.407 & -0.310 \\
City & Lag (days) & Temperature & & \\
Jeddah & 0 & 0.661 & & \\
& 1 & 0.622 & & \\
& 2 & 0.613 & & \\
& 3 & 0.604 & & \\
\hline
\end{tabular}

2020; Wang et al. 2020; Yuan et al. 2021) reported that the spread of COVID-19 is related to temperature. In our study, as we can see from Table 4, the temperature at 1- to 3-day lag had a greater impact on COVID-19 case counts than other variables in Medina. For example, Zoran et al. (2020) found that the maximum temperature might have a major effect on COVID-19 transmission. Behnood et al. (2020) indicated significant association between temperature and COVID-19 infection rates.

In Poisson and ZIP regression analysis for Riyadh (cf. Table 5), we perceived that the number of daily cases at 1-day lag was linked with increased case counts. Each $1^{\circ} \mathrm{F}$ increase in temperature on the same day at 1- and 3-day lag was associated with the prevalence of COVID-19 cases, while each $1^{\circ} \mathrm{F}$ increase in temperature at 2-day lag was likely to decrease the cases. Each $1 \%$ rise in humidity on the same day, at 1- and 3-day lag, was related to the increase of daily cases. At the same time, a $1 \%$ increase in humidity at 2-day lag leads to a decline in cases. Furthermore, each 1 mph increase in wind speed on the same day at 1- and 3-day lag was connected with reduced case counts. But each $1 \mathrm{mph}$ increase in wind speed at 2-day lag was likely to lead rise in the case of counts. It was also observed that the temperature at 1 and 3 days was related negatively to the probability of the occurrence of COVID-19. In NB and ZINB regression analysis (cf. Table 5), we found that number of cases at 1-day lag was associated with the rise in case counts. Each $1^{\circ} \mathrm{F}$ increase in temperature on the same day at 3-day lag was correlated to the rise of case counts. Also, each $1 \%$ increase in humidity and $1 \mathrm{mph}$ increase in wind speed at 3-day lag were related to increased case counts. Also, the probability of the occurrence of COVID-19 case counts was negatively associated with the temperature at 1- and 3-day lag. Hence, we perceived that the temperature at 3-day lag and wind speed on the same day and 3-day lag had a greater impact on the COVID-19 epidemic than other variables in Riyadh. This finding is consistent with some previous studies (Auler et al. 2020; Guo et al. 2021; Menebo 2020; Şahin 2020). For instance, Wei et al. (2020) reported that the temperature and wind speed significantly affected the confirmed cases of COVID-19 in the spring in Beijing. Gupta (2020) identified that wind speed promoted COVID-19 spread in Turkey.

The output of Poisson and ZIP regression analysis for Jeddah (cf. Table 6) showed that the rise in daily cases at 1-day lag was likely to lead to an increase in COVID-19 daily case counts. Each $1{ }^{\circ} \mathrm{F}$ increase in temperature on the same day and temperature at 2- to 3-day lag was related to rising of COVID-19 daily case counts, while $1^{\circ} \mathrm{F}$ increase in temperature at 1-day lag was associated with the decline of cases. It seemed no explanatory variable had a significant impact on the probability of COVID-19 occurrence. The NB and ZINB regression analysis (cf. Table 6) indicated that daily cases at 1-day lag were likely to increase COVID-19 daily case counts. Moreover, we found that each $1^{\circ} \mathrm{F}$ increase in temperature on the same day and at 2- to 3-day lag was correlated with increased case counts. Also, it was observed that no explanatory variable had a significant effect on the probability of occurrence of COVID-19 case counts. These results showed that the temperature on the same day and at 1-day lag had a greater impact on COVID-19 case counts in Jeddah. Similar results were found in previous research, which showed the contribution of temperature to COVID-19 transmission (Chien and Chen 2020; Sarkodie and Owusu 2020; Yang et al. 2021). For example, Bhardwaj and Agrawal (2020) presented that a modest rise in temperature will increase spatial distances and viral exposure risk due to a rise in the intensity of Brownian motion of air particles. Sharma et al. (2021) showed that the risk of coronavirus infection in people was affected by air pressure and temperature.

The LRT statistic results (c.f. Tables 4, 5, and 6) in three cities indicated that the $P$ values were less than 0.01 , which led to the rejection of the null hypothesis. So, the significant findings of the NB model gave evidence of overdispersion in the data set of each city. After finding the significant results of the overdispersion test, we used the Vuong test to test for zero inflation (NB vs ZINB). The findings (c.f. Tables 4, 5, and 6) revealed that the ZINB model was more appropriate as compared to the NB model at $1 \%$ level of significance for all three cities. Also, the other model selection criteria, such as AIC and BIC, were in favor of the ZINB model. This finding is consistent with early research findings; for example, Benita and Gasca-Sanchez (2021) strongly favored ZINB regression to model COVID-19 cases. To estimate the relationship between voter turnout and COVID-19 incidence, Flanders et al. (2020) employed ZINB regression. After evaluating the comparative results (c.f. Tables 4, 5, and 


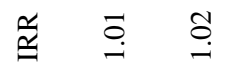

苟

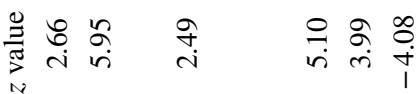

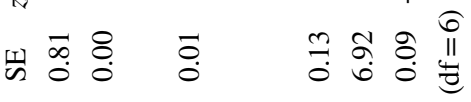

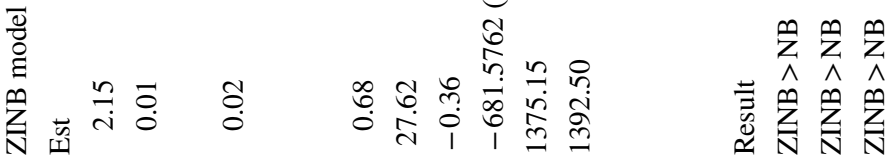

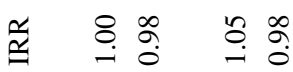

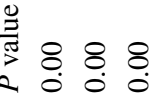

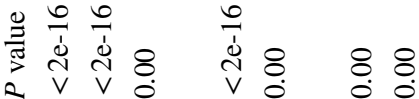

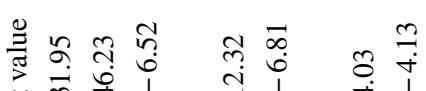

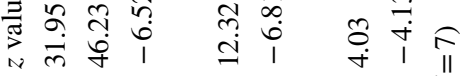

w

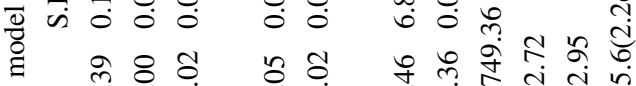

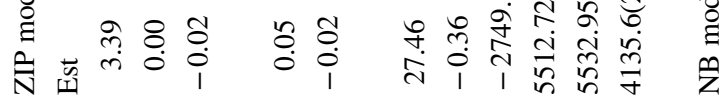

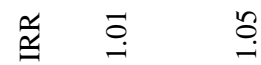

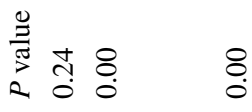

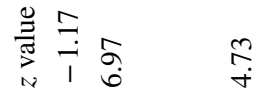

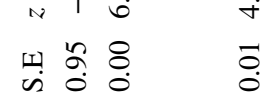

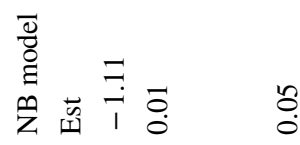

ํㅏㅁ

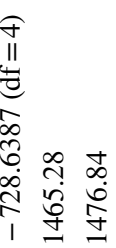

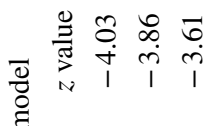

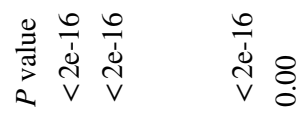

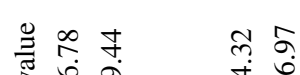

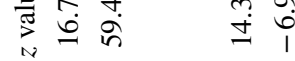

w 응 \& 8

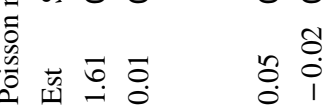

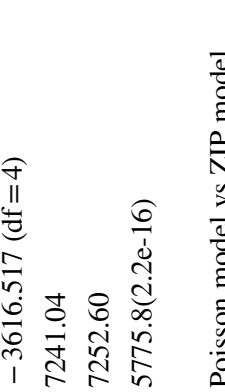

$=220$

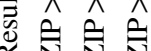

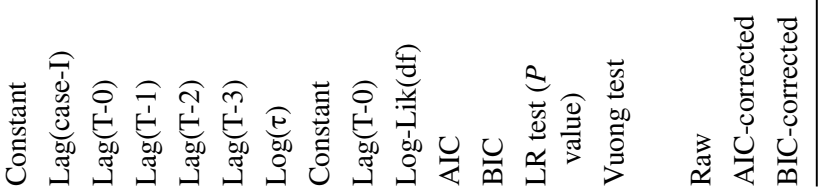




\begin{tabular}{|c|c|c|}
\hline 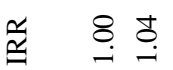 & $\stackrel{n}{\sigma}$ & \\
\hline 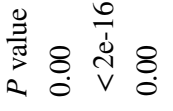 & $\stackrel{8}{0}$ & 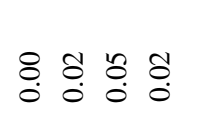 \\
\hline 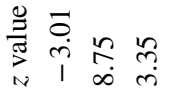 & $\stackrel{n}{m}$ & 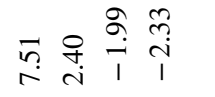 \\
\hline 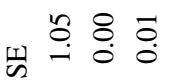 & Бे. & 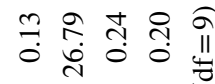 \\
\hline
\end{tabular}

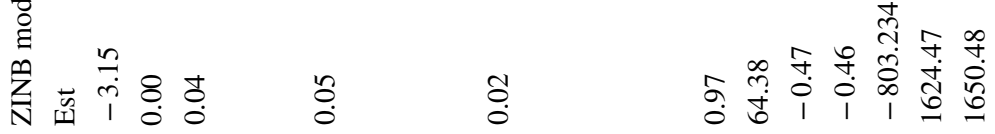

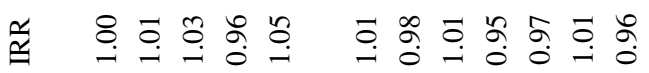

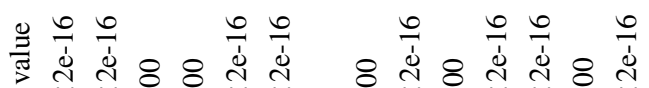

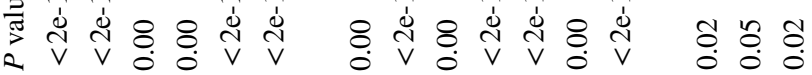

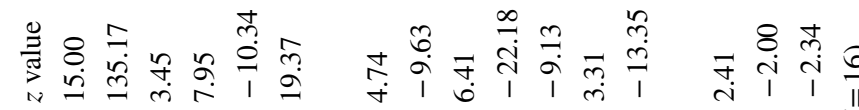

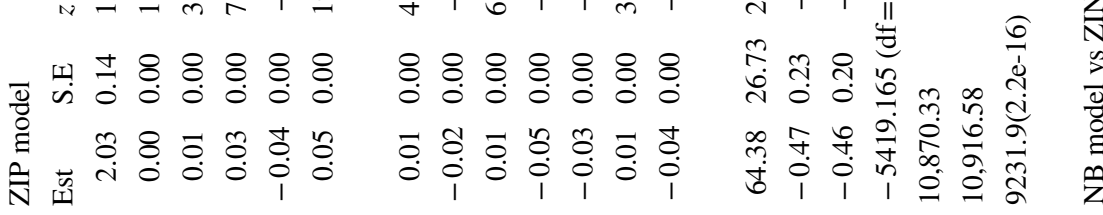

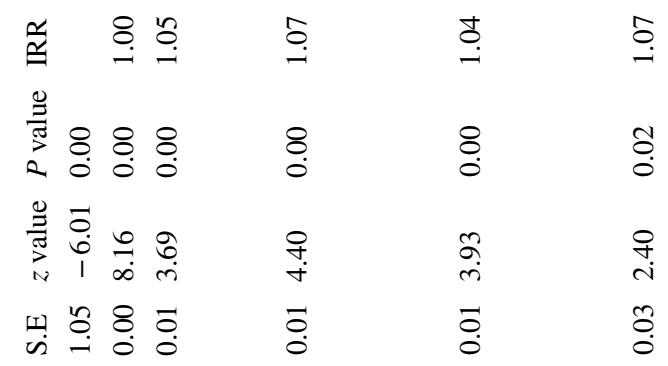

$\frac{\bar{\theta}}{0}$

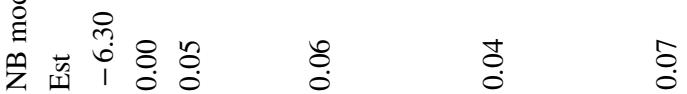

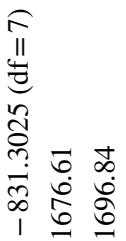

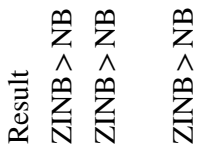

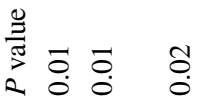

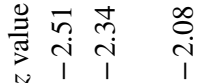

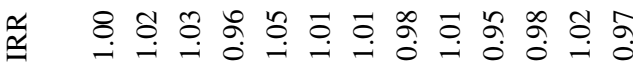

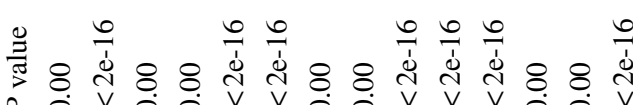

v $v \circ+a$ o

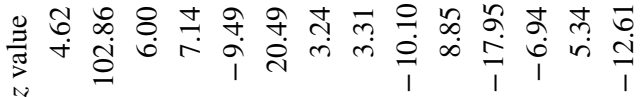

离

泀

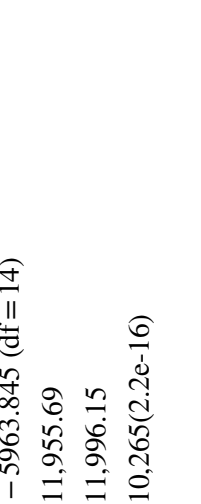

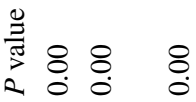

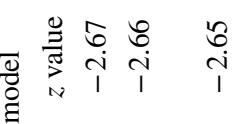

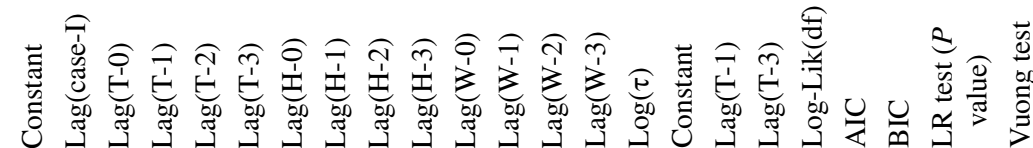


$\stackrel{0}{\cong} \stackrel{0}{\underline{0}}$

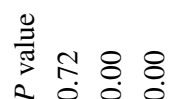

¿ :

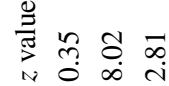

๙ุ

س

$\begin{array}{lll}m & 0 \\ 0 & 0 & \text { II } \\ 0 & 0 & \end{array}$

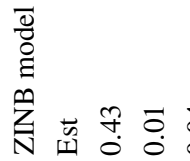

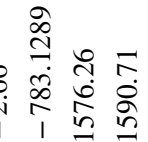

눙ำ

๕

$\approx \mathbb{N} \in$

? $\div \div \div 0$

\& 0 v

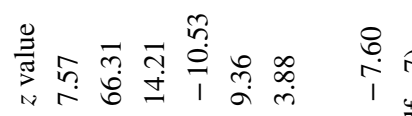

उ

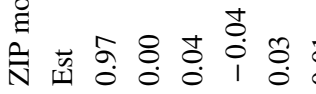

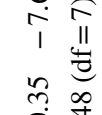

\&

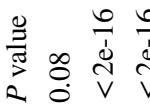

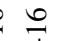

$2,0 \mathrm{~V}$

$\stackrel{8}{0}:$

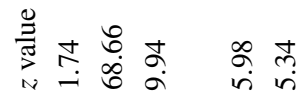

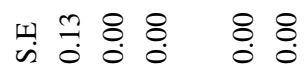

ब্

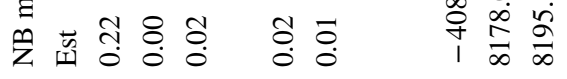

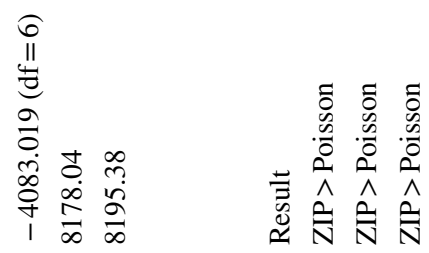

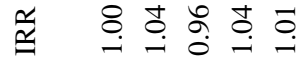

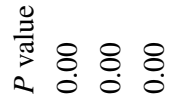

$\cong \quad \div 0 \div 0$

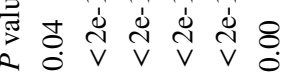

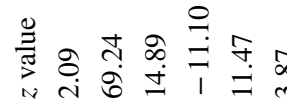

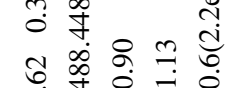

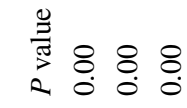

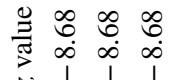

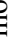

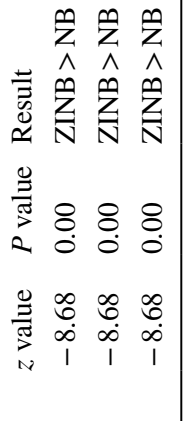

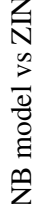

되 $\because 88$ \& \&

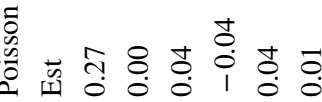

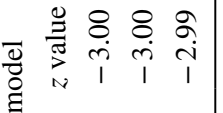

$\overrightarrow{0}$

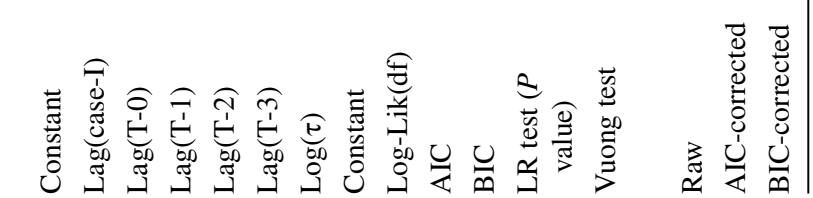


6), we found that the ZINB model fits best the COVID-19 case counts as compared to other models.

\section{Conclusion}

As COVID-19 is a continuous and increasing phenomenon; thus, it was vital to see the effect of meteorological factors on the disease. We examined the impact of meteorological factors on COVID-19 cases after considering the excess of zero counts. Our data revealed a significant correlation between COVID-19 cases and climatic parameters for all three most contaminated cities under study. For temperature as a meteorological factor, we found a significant positive association between COVID-19 case counts and temperature on the same day and past days. We also found that humidity and wind speed were associated negatively at various lags with COVID-19 case counts.

The epidemic of COVID-19 in Medina, Riyadh, and Jeddah indicated overdispersed daily cases and zero cases on some days. When the response variable is in a discrete nature, then the Poisson model is preferred. The ZIP and ZINB models are suitable for modeling a data set with excess zero counts (Cameron and Trivedi 2013; Lambert 1992), and in the case of the overdispersion, NB model is considered appropriate (McCullagh and Nelder 1989; Nelder and Wedderburn 1972). Hence, we built four models to fit COVID-19 daily case counts for each city. Besides, we compared these models and perceived that the ZINB model is the best-fitted model for COVID-19 daily cases in Medina, Riyadh, and Jeddah.

The Kingdom of Saudi Arabia has a warm, dry climate with high temperatures and low annual rainfall. We found that, in three cities of KSA, an increase in temperature was not necessarily associated with the decline of cases in contradiction to the hypothesis. Although our findings show an independent impact of meteorological factors on COVID-19 case counts, the public health protective measures play a vital role in controlling the epidemic of COVID-19.

This research adds to the domain of pandemic management in both a practical and theoretical sense. The findings provide a better knowledge of the situation and may aid in adopting suitable measures to implement pandemic response policies and activities as needed in a fast and effective way. For instance, our results ascertained that temperature, humidity, and wind speed contribute significantly towards the incidence of COVID-19; therefore, it can be argued that government needs to impose strict regulations during high temperature, humidity, and low wind speed. The most important implication is that, in pandemics, where widespread and effective vaccination is not possible, government preparation should be longer term, taking into account weather effects, and establish public health and safety directions accordingly.
For instance, with the proper weather-based changes, mask and distancing guidelines should be followed. Also, a robust response to the pandemic can be created by combining meteorological and medical expertise. In conclusion, our findings shed light on the association between meteorological factors and COVID-19 case counts in three cities of KSA. Overall, the areas with high temperature, low wind speed, and high humidity favor the rise in COVID-19 case counts. This study could be useful for forecasting agencies in developing predictive tools for COVID-19 prevention in KSA. The selected models could be used to predict the probability of COVID-19 occurrence and the number of cases in three cities of KSA. Furthermore, experts may reconsider and alter policy approaches in order to lessen the total impact on the environment and economy while still adhering to sustainable development.

There are certain limitations to work. Other variables regulating disease transmissions, such as air pollution, water pollution, ultraviolet radiation, rainfall, atmospheric pressure, and geographical characteristics, were not examined. These influencing variables should be taken into account in models like the ones utilized in this study. For future studies, the present work can be extended to other parts of the world with extensive data set and varying weather situations. The optimal temperature to counter-effect the spread of disease is yet to be investigated to the best of our knowledge regarding COVID-19 vaccines.

Author contribution Conceptualization, AI, TM; methodology, AI and TM; software, AI and TM; validation, TM and SHR; formal analysis, $\mathrm{AI}$; investigation, TM and $\mathrm{WH}$; resources, $\mathrm{WH}$ and SHR; data curation, AI; writing original draft preparation, $\mathrm{AI}$ and $\mathrm{TM}$; writing — review and editing, WH and SHR; visualization, WH and SHR; supervision, TM, WH and SHR; project administration, WH; all authors have read and agreed to the published version of the manuscript.

(Note: We have used initials for each author).

Data availability Data is publicly available on the mentioned websites in the text of manuscript.

\section{Declarations}

Ethics approval and consent to participate Not applicable.

Consent for publication Not applicable.

Competing interests The authors declare no competing interests.

\section{References}

Agresti A (2003) Categorical data analysis, 482. John Wiley \& Sons Al-Ahdal MN, Al-Qahtani A, Ali Rubino S (2012) Coronavirus respiratory illness in Saudi Arabia. The J Infec Dev Ctries 6:692-694 
Alsubaie S, Temsah MH, Al-Eyadhy AA, Gossady I, Hasan GM, AlRabiaah A, Jamal AA, Alhaboob AA, Alsohime F, Somily AM (2019) Middle East respiratory syndrome coronavirus epidemic impact on healthcare workers' risk perceptions, work and personal lives. J Infec Dev Ctries 13:920-926

Auler A, Cássaro F, Da Silva V, Pires L (2020) Evidence that high temperatures and intermediate relative humidity might favor the spread of COVID-19 in tropical climate: a case study for the most affected Brazilian cities. Sci Total Environ 729:139090

Bashir MF, Ma B, Bilal KB, Bashir MA, Tan D, Bashir M (2020) Correlation between climate indicators and COVID-19 pandemic in New York, U.S.A. Sci Total Environ 728:1-4

Behnood A, Golafshani EM, Hosseini SM (2020) Determinants of the infection rate of the COVID-19 in the US using ANFIS and virus optimization algorithm (VOA). Chaos Solitons Fractals 139:110051

Benita F, Gasca-Sanchez F (2021) The main factors influencing COVID-19 spread and deaths in Mexico: a comparison between phases I and II. Appl Geogr 134:102523

Bhardwaj R, Agrawal A (2020) Likelihood of survival of coronavirus in a respiratory droplet deposited on a solid surface. Phys Fluids 32:061704

Cameron AC, Trivedi PK (2013) Regression analysis of count data, 53. Cambridge University Press

Cao C, Chen W, Zheng S, Zhao J, Wang J, Cao W (2016) Analysis of spatiotemporal characteristics of pandemic SARS spread in mainland China. BioMed Res Intl 2016:1-12

Chan JF-W, Yuan S, Kok K-H, To KK-W, Chu H, Yang J, Xing F, Liu J, Yip CC-Y, Poon RW-S (2020) A familial cluster of pneumonia associated with the 2019 novel coronavirus indicating personto-person transmission: a study of a family cluster. The Lancet 395:514-523

Chien L-C, Chen L-W (2020) Meteorological impacts on the incidence of COVID-19 in the US. Stoch Environ Res Risk Assess 34:1675-1680

El-Masry EA, Mohamed RA, Ali RI, Al Mulhim MF, Taha AE (2021) Novel coronavirus disease-related knowledge, attitudes, and practices among the residents of Al-Jouf region in Saudi Arabia. J Infec Dev Ctries 15:22-39

Flanders WD, Flanders WD, Goodman M (2020) The association of voter turnout with county-level coronavirus disease 2019 occurrence early in the pandemic. Ann Epidemiol 49:42-49

Fu S, Wang B, Zhou J, Xu X, Liu J, Ma Y, Li L, He X, Li S, Niu J (2021) Meteorological factors, governmental responses and COVID-19: evidence from four European countries. Environ Res 194:110596

Gale P, Brouwer A, Ramnial V, Kelly L, Kosmider R, Fooks A, Snary E (2010) Assessing the impact of climate change on vector-borne viruses in the EU through the elicitation of expert opinion. Epidemiol Infect 138:214-225

Gao C, Li S, Liu M, Zhang F, Achal V, Tu Y, Zhang S, Cai C (2021) Impact of the COVID-19 pandemic on air pollution in Chinese megacities from the perspective of traffic volume and meteorological factors. Sci Total Environ 773:145545

Guan W-j, Ni Z-y, Hu Y, Liang W-h, Ou C-q, He J-x, Liu L, Shan H, Lei C-1, Hui DS (2020) Clinical characteristics of coronavirus disease 2019 in China. N Engl J Med 382:1708-1720

Guo C, Bo Y, Lin C, Li HB, Zeng Y, Zhang Y, Hossain MS, Chan JW, Yeung DW, Kwok K-O (2021) Meteorological factors and COVID-19 incidence in 190 countries: an observational study. Sci Total Environ 757:143783

Gupta D (2020) Effect of ambient temperature on COVID-19 infection rate. Available at SSRN 3558470

Haq W, Raza SH, Malik MW (2020) Missed takes towards a pandemic of COVID-19? A systematic literature review of Coronavirus related diseases in Pakistan. J Infect Dev Ctries 14(07):726-31
Haq W, Raza SH, Mahmood TJP (2020) The pandemic paradox: domestic violence and happiness of women. Front Psych 8:e10472

HuangCL W (2020) Clinicalfea- tures of patients infected with 2019 novel coronavirus in Wuhan. China 395:497-506

Iqbal N, Fareed Z, Shahzad F, He X, Shahzad U, Linae M (2020) The nexus between COVID-19, temperature and exchange rate in Wuhan city: new findings from partial and multiple wavelet coherence. Sci Total Environ 729:1-9

Islam ARMT, Hasanuzzaman M, Azad MAK, Salam R, Toshi FZ, Khan MSI, Alam GM, Ibrahim SM (2021) Effect of meteorological factors on COVID-19 cases in Bangladesh. Environ Dev Sustain 23:9139-9162

Jackman S (2010) pscl: Classes and methods for R. Developed in the Political Science Computational Laboratory, Stanford University. Department of Political Science, Stanford University, Stanford, CA. R package version 1.03. 5. http://www.pscl.stanf ord.edu/. Accessed July 2021

Jain S, Sharma T (2020) Social and travel lockdown impact considering coronavirus disease (COVID-19) on air quality in megacities of India: present benefits, future challenges and way forward. Aerosol Air Qual Res 20:1222-1236

Jiang F, Deng L, Zhang L, Cai Y, Cheung CW, Xia Z (2020) Review of the clinical characteristics of coronavirus disease 2019 (COVID19). J Gen Inter Med 35:1545-1549

Khursheed A, Mustafa F, Akhtar A (2021) Investigating the roles of meteorological factors in COVID-19 transmission in Northern Italy. Environ Sci Pollut Res 28:48459-48470

Lambert D (1992) Zero-inflated Poisson regression, with an application to defects in manufacturing. Technometrics $34: 1-14$

Li S 2011 Environmentally mediated transmission models for influenza and the relationships with meteorological indices. Epidem Sci Vol. Doctor of Philosophy, pp 1-181

Lin C, Lau AK, Fung JC, Guo C, Chan JW, Yeung DW, Zhang Y, Bo Y, Hossain MS, Zeng Y (2020) A mechanism-based parameterisation scheme to investigate the association between transmission rate of COVID-19 and meteorological factors on plains in China. Sci Total Environ 737:140348

Liu J, Zhou J, Yao J, Zhang X, Li L, Xu X, He X, Wang B, Fu S, Niu T (2020) Impact of meteorological factors on the COVID19 transmission: a multi-city study in China. Sci Total Environ $726: 138513$

Lofgren E, Fefferman NH, Naumov YN, Gorski J, Naumova EN (2007) Influenza seasonality: underlying causes and modeling theories. J Virol 81:5429-5436

Lowen AC, Mubareka S, Steel J, Palese P (2007) Influenza virus transmission is dependent on relative humidity and temperature. PLoS Path 3:1470-1476

Luo W, Majumder M, Liu D, Poirier C, Mandl K, Lipsitch M, Santillana M (2020) The role of absolute humidity on transmission rates of the COVID-19 outbreak. MedRxiv 1-7

Mahmood T (2020) Generalized linear model based monitoring methods for high-yield processes. Qual Reliab Eng Intl 36:1570-1591

Mazhar Iqbal M, Abid I, Hussain S, Shahzad N, SohailWaqas M, Jawed Iqbal M (2020) The effects of regional climatic condition on the spread of COVID-19 at global scale. Sci Total Environ 739:140101

McCullagh P, Nelder JA (1989) Generalized linear models 2nd edition chapman and hall. London, UK

Menebo MM (2020) Temperature and precipitation associate with Covid-19 new daily cases: a correlation study between weather and Covid-19 pandemic in Oslo. Norway. Sci Total Environ 737:139659

Nasar A, Muna A-M, Buthaina A-D, Halima A-I, Shadia A-B (2020) A review of the prevalence of COVID-19 in the Arab world. J Infec Dev Ctries 14:1238-1245 
Nelder J, Wedderburn R (1972) Generalized Linear Models. J R Stats Soc Ser A (Gen) 135:370-384

Arab News (2020) Saudi Arabia records major decline in virus tally since March. ARABNEWS

Obied DA, Alhamlan FS, Al-Qahtani AA, Al-Ahdal MN (2020) Containment of COVID-19: the unprecedented response of Saudi Arabia. J Infec Dev Ctries 14:699-706

Oliveiros B, Caramelo L, Ferreira NC, Caramelo F (2020) Role of temperature and humidity in the modulation of the doubling time of COVID-19 cases. MedRxiv 1-13

Pani SK, Lin N-H, RavindraBabu S (2020) Association of COVID-19 pandemic with meteorological parameters over Singapore. Sci Total Environ 740:140112

Park JE, Son WS, Ryu Y, Choi SB, Kwon O, Ahn I (2020) Effects of temperature, humidity, and diurnal temperature range on influenza incidence in a temperate region. Influenza Other Respir Viruses 14:11-18

Public Health England (2020) COVID-19: epidemiology, virology and clinical features. Public Health England

Qadah T (2020) Knowledge and attitude among healthcare workers towards COVID-19: a cross sectional study from Jeddah city, Saudi Arabia. J Infec Dev Ctries 14:1090-1097

Rendana M (2020) Impact of the wind conditions on COVID-19 pandemic: a new insight for direction of the spread of the virus. Urban Climate 34:100680. https://doi.org/10.1016/j.uclim.2020.100680

Rizwan K, Rasheed T, Khan SA, Bilal M, Mahmood T (2020) Current perspective on diagnosis, epidemiological assessment, prevention strategies, and potential therapeutic interventions for severe acute respiratory infections caused by 2019 novel coronavirus (SARSCoV-2). Hum Vaccines Immunother 16(12):3001-3010

Şahin M (2020) Impact of weather on COVID-19 pandemic in Turkey. Sci Total Environ 728:138810

Sarkodie SA, Owusu PA (2020) Impact of meteorological factors on COVID-19 pandemic: evidence from top 20 countries with confirmed cases. Environ Res 191:110101

Shahzad K, Shahzad U, Iqbal N, Shahzad F, Fareed Z (2020) Effects of climatological parameters on the outbreak spread of COVID19 in highly affected regions of Spain. Environ Sci Pollut Res 27:39657-39666

Shaman J, Kohn M (2009) Absolute humidity modulates influenza survival, transmission, and seasonality. Proc Natl Acad Sci 106:3243-3248

Sharma GD, Bansal S, Yadav A, Jain M, Garg I (2021) Meteorological factors, COVID-19 cases, and deaths in top 10 most affected countries: an econometric investigation. Environ Sci Pollut Res 28:28624-28639

Shi P, Dong Y, Yan H, Zhao C, Li X, Liu W, He M, Tang S, Xi S (2020) Impact of temperature on the dynamics of the COVID-19 outbreak in China. Sci Total Environ 728:138890

Stott P (2016) How climate change affects extreme weather events. Science 352:1517-1518

Suhaimi NF, Jalaludin J, Latif MT (2020) Demystifying a possible relationship between COVID-19, air quality and meteorological factors: evidence from Kuala Lumpur, Malaysia. Aerosol Air Qual Res 20:1520-1529
Tan J, Mu L, Huang J, Yu S, Chen B, Yin J (2005) An initial investigation of the association between the SARS outbreak and weather: with the view of the environmental temperature and its variation. J Epidemiol Commun Health 59:186-192

Venables W, Ripley B, Venables W (2002) Modern applied statistics with S, 4th edn. Springer, New York, pp 435-446

Vuong QH (1989) Likelihood ratio tests for model selection and nonnested hypotheses. Econometrica: J Econom Soc 1989:307-333

Wang J, McMichael AJ, Meng B, Becker NG, Han W, Glass K, Wu J, Liu X, Liu J, Li X (2006) Spatial dynamics of an epidemic of severe acute respiratory syndrome in an urban area. Bull WHO 84:965-968

Wang M, Jiang A, Gong L, Luo L, Guo W, Li C, Li, H (2020) Temperature significant change COVID-19 Transmission in 429 cities. MedRxiv 1-19

Wei J-T, Liu Y-X, Zhu Y-C, Qian J, Ye R-Z, Li C-Y, Ji X-K, Li H-K, Qi C, Wang Y (2020) Impacts of transportation and meteorological factors on the transmission of COVID-19. Int J Hyg Environ Health 230:113610

WHO (2020a) Coronavirus: WHO chief hails Saudi Arabia's COVID19 measures during Hajj. Al Arabiya English

WHO (2020b) Novel Coronavirus - China. World Health Organization

WHO (2020c) WHO Director-General's remarks at the media briefing on 2019-nCoV. World Health Organization

WHO (2020d) Coronavirus disease (COVID-19) outbreak situation. World Health Organization

Yang X-D, Li H-L, Cao Y-E (2021) Influence of meteorological factors on the COVID-19 transmission with season and geographic location. Int J Environ Res 18:484

Yao Y, Pan J, Liu Z, Meng X, Wang W, Kan H, Wang W (2020) No association of COVID-19 transmission with temperature or UV radiation in Chinese cities. Eur Respiratory 55:1-9

Yuan J, Wu Y, Jing W, Liu J, Du M, Wang Y, Liu M (2021) Non-linear correlation between daily new cases of COVID-19 and meteorological factors in 127 countries. Environ Res 193:110521

Zangari S, Hill DT, Charette AT, Mirowsky JE (2020) Air quality changes in New York City during the COVID-19 pandemic. Sci Total Environ 742:1404965

Zhu N, Zhang D, Wang W, Li X, Yang B, Song J, Zhao X, Huang B, Shi W, Lu R (2020) A novel coronavirus from patients with pneumonia in China, 2019. N Engl JMed 382:727-733

Zoran MA, Savastru RS, Savastru DM, Tautan MN (2020) Assessing the relationship between surface levels of PM2. 5 and PM10 particulate matter impact on COVID-19 in Milan, Italy. Sci Total Environ 738:139825

Publisher's note Springer Nature remains neutral with regard to jurisdictional claims in published maps and institutional affiliations. 